\section{EXPLORING GRANDPARENTHOOD WITHIN THE CONTEXT OF GRANDCHILD DISABILITY: GRANDPARENTS' PERSPECTIVES}

H. Merrick ${ }^{1}$, S. Moffatt, $\mathrm{PhD}^{2}$, L. Pennington, $\mathrm{PhD}^{3}$, $\mathrm{J}$. McLaughlin, $\mathrm{PhD}^{4}, 1$. Institute of Health and Society, Newcastle University, Newcastle upon Tyne, United Kingdom, Newcastle upon Tyne, England, United Kingdom, 2. Institute of Health and Society, Newcastle University, Newcastle upon Tyne, United Kingdom, 3. Institute of Health and Society, Newcastle University, Newcastle upon Tyne, United Kingdom, 4. Sociology, School of Geography, Politics and Sociology, Newcastle University, Newcastle upon Tyne, United Kingdom

Available evidence indicates that grandparents can play a crucial role in supporting and caring for disabled grandchildren and the entire family unit, yet the lived experiences of grandparenting in this context has received scant attention in research, policy or practice. This study explored grandparents' perspectives on their role and intergenerational relationships within the family as they age. Narrative interviews were conducted with 20 grandparents (aged 60-85 years), who had a grandchild with a range of disabilities (aged 4-19 years). Key themes emerging include: 'family keeping' (support, protection), 'concern for the future' (impact of ageing, worry), 'changing times' (stepping back, growing up), 'grandparenting' (being there, pride, adjustments, negotiation), 'knowledge and advice' (acquiring new knowledge, professional and personal experience). The results of this study give a voice to a previously under-researched group and help inform key debates, such as how extending working life policies can impact on families with disabled children.

\section{Y CYMRY CYMRAEG: PEOPLE, PLACE, LANGUAGE AND SOCIAL EXCLUSION - A CASE STUDY OF RURAL-DWELLING OLDER PEOPLE IN WALES} B. Winter ${ }^{1}, \mathrm{~V}$. Burholt, $\mathrm{PhD}^{2}, 1$. Centre for Innovative Ageing, Swansea University, Swansea, Wales, United Kingdom, 2. Centre for Innovative Ageing, College of Human and Health Sciences, Swansea University

The proportion of Welsh speakers in Wales has declined from $50 \%$ in 1901 to $19 \%$ in 2011 . This study investigates the ways in which language (linguistic identities and proficiencies, language ideologies) intersects with social exclusion from social relations and culture in different rural environments. Three types of rural areas were selected: (i) remote $\&$ affluent; (ii) less remote $\&$ deprived; (iii) accessible \& deprived. 30 life history interviews and 3 focus groups were conducted with older people ( $\geq 60$ years). The results show 'how' and 'why' social exclusion manifests itself. The decline of Welsh language had the greatest impact upon the oldest old $(80+$ years $)$ who experienced greatest exclusion from social resources and culture. A correlation was found between language, socio-economic status and place: the remote and affluent area had the highest proportion of Welsh speakers yet some of the greatest levels of old-age social exclusion.

\section{SESSION 2180 (SYMPOSIUM)}

POLICY SERIES: CONGRESSIONAL UPDATE

Chair: B.W. Lindberg, The Gerontological Society of

America, Washington, District of Columbia
This popular annual session will provide cutting-edge information on what the 115th Congress has and has not accomplished to date, and what may be left for the lame duck session to address. Speakers will discuss key issues such as Social Security, Medicare, Medicaid, and the Older Americans Act, and how older adults rate the importance of various issues. Predictions for the 116th Congress will abound. Feel free to come and add your challenges and prophecies to the list. Hill staffers, advocates, and lobbyists will present.

B. W. Lindberg, The Gerontological Society of America, Washington, District of Columbia, United States

E. Solway, University of Michigan, Ann Arbor, Michigan, United States

S. Khasawinah, U.S. Senate Special Committee on Aging, Washington, District of Columbia, United States

\section{SESSION 2185 (SYMPOSIUM)}

\section{AGING POLICY IN THE TRUMP ERA}

Chair: E.A. Miller, University of Massachusetts Boston, Boston, Massachusetts

Co-Chair: M.K. Gusmano, Rutgers University School of

Public Health, New Brunswick, New Jersey

Discussant: D.K. Jones, Boston University, Boston,

Massachusetts

The election of Donald Trump to the presidency has inaugurated a period of uncertainty and change in the American political sphere. Perhaps in no area is the potential ramifications of the Trump presidency and unified Republican control of Congress clearer than in aging policy. Between 2010 and 2050 the proportion of the U.S. population aged 65 years or older is projected to increase from $13 \%$ to $20 \%$. Population aging creates opportunities and challenges for elders, their families, and society in general. The Obama administration chose to meet these challenges, in part, by seeking to expand the social safety net. By contrast, the Trump administration has largely been supportive of Republican priorities to draw back on the federal government's commitment to programs intended to support an aging population, despite rhetoric to the contrary during the presidential campaign. Recently, President Trump signed the Republican tax reform bill which repealed the ACA's individual mandate and reduced federal tax revenues by about $\$ 1.5$ trillion dollars over 10 years, potentially triggering across the board cuts to federal domestic programs supporting health and long-term care, housing, and retirement. This panel assembles leading experts to examine the implications of these and other changes for aging policy in the Trump era. Participants include: Marc Cohen and Judy Feder (financing long-term services and supports), Robyn Stone (Housing), Christian Weller (workforce and retirement), and Pamela Nadash (health care). Edward Alan Miller will chair the panel; Michael Gusmano will serve as co-chair and David $\mathrm{K}$. Jones as discussant.

FINANCING LONG-TERM SERVICES AND SUPPORTS: CHALLENGES, GOALS, AND NEEDED REFORMS

M. Cohen ${ }^{1}$, J. Feder, $\mathrm{PhD}^{2}$, 1. University of Massachusetts

Boston, Boston, Massachusetts, United States, 2.

Georgetown University, Washington, DC, USA 
The need for long-term services and supports (LTSS) presents a growing financial burden on care recipients, their families, and state Medicaid budgets. Strategies for addressing this problem pose both a policy design and a political challenge. This presentation assesses current LTSS policy directions and politics -- specifically, the movement to constrain, rather than enhance, federal financing for LTSS and the counter pressures necessary to strengthen meaningful insurance protection. While the political environment has become even less conducive to expansion of public benefits, the underlying problem of LTSS financing will grow and persist. And politics change. Thus, choices need to be made that bridge the political divide, including development of a new public-private partnership based on a public program to cover "back-end" or catastrophic costs, plus measures making private insurance more attractive for the "up-front" risk, an approach that has recently been endorsed by a number of bipartisan groups.

\section{THE HOUSING CHALLENGES OF LOW-INCOME OLDER ADULTS AND THE ROLE OF FEDERAL POLICY \\ R.I. Stone, LeadingAge, Washington, D.C, District of Columbia, United States}

Adequate housing is critical for low-income older adults who face affordability and accessibility challenges affecting their quality of life, health and ability to live independently in their communities. This presentation examines the federal policy role in meeting the housing and housing-relatedneeds of the low-income elderly population. The availability of publicly subsidized units and vouchers is woefully inadequate. Although access to affordable and accessible housing options has been a growing challenge for several decades, the Trump administration and Republican-majority Congress has an agenda and specific budgetary, administrative and legislative proposals that would worsen the housing situation today and into the future. The aging of America over the next two decades and the lack of investment in affordable senior housing and related programs requires a Call to Action for stakeholders in the public and private sectors to jointly develop a comprehensive national senior housing policy agenda and implementation strategy.

\section{POLICY RESPONSES DURING THE TRUMP ADMINISTRATION TO OLDER PEOPLE'S GROWING ECONOMIC RISK EXPOSURE}

C. Weller ${ }^{1}$, M.E. Tolson, $\mathrm{MS}^{2}, 1$. University of

Massachusetts Boston, Boston, Massachusetts, United

States, 2. University of Massachusetts, Boston, Boston, MA, USA

Economic risk exposure especially through increased labor market volatility and growing caregiving responsibilities has risen for older Americans. At the same time, key protections such as unemployment insurance and Social Security have declined, while other protections, particularly in the private market are limited or non-existent. In virtually all instances, the Trump administration has already moved to weaken existing protections. And, it has offered either no proposals or very limited proposals to increase protections in the private sector, for instance, by offering households tax deductions for caregiving costs. This approach would largely benefit higher-income households and offer few or no benefits to low-income and middle-income households. As a result, an aging population will increasingly face rising economic risks on their own.

\section{THE GOP'S TRANSFORMATION OF AMERICAN HEALTH CARE: THE STAKES FOR OLDER AMERICANS}

P. Nadash ${ }^{1}$, E. Alan Miller, $\mathrm{PhD}^{2}$, D.K. Jones, $\mathrm{PhD}^{3}$, M.K. Gusmano, $\mathrm{PhD}^{4}$, S. Rosenbaum, JD 5 , 1. University of Massachusetts Boston, Boston, Massachusetts, United States, 2. University of Massachusetts Boston, Boston, MA, USA; Brown University, Providence, RI, USA, 3. Boston University, Boston, MA, USA, 4. Rutgers University, New Brunswick, NJ, USA; The Hastings Center, Garrison, NY, USA, 5. The George Washington University, Washington, DC

The transformation of the American health care system is at the foremost of the Republican agenda. This presentation reviews Republican-led efforts to repeal the health insurance coverage provisions of the Patient Protection and Affordable Care Act (ACA), institute block grants or spending caps in Medicaid, and adopt vouchers for purchasing private insurance under Medicare. It also analyzes the implicatisons of the Republican tax reform bill signed by President Trump which, in fact, repealed the ACA's individual mandate and reduced federal tax revenues by $\$ 1.5$ trillion dollars over 10 years, possibly resulting in future reductions in spending on Medicare and Medicaid. It points out that older adults have emerged as perhaps the most important population group impacted by the GOP's health care agenda, both because of their dependence on Medicare and Medicare, and because it was they who bore the brunt of the failures of the pre-ACA U.S. health insurance patchwork.

\section{SESSION 2190 (SYMPOSIUM)}

\section{LONELINESS IN RURAL AREAS-LEARNING FROM RESEARCH, PRACTICE AND LIFE}

Chair: R. O'Sullivan, Institute of Public Health in Ireland, Belfast, Dublin

Co-Chair: L. Holley, University of Nebraska at Omaha, Omaha, Nebraska

Discussant: C. Ford, University of Alabama, Tuscaloosa, Alabama

The issue of chronic loneliness has been described as the new epidemic affecting modern society. The association between loneliness with poorer health outcomes has been well established. However, the specific issue of those reporting loneliness in rural areas has received less attention and debate. This symposium illustrates the challenges faced by seniors in rural settings in both the USA and Europe. It shines a spotlight on environmental, gender, housing, LGBTQ community, as well as mental health in rural areas in a bid to increase understanding, debate and discussion. The symposium aims to answer the question: are there particular characteristics of rural loneliness that may have implications for public health and community practice? Burholt and colleagues use data from the UK (rural Wales) to examine individual and situational risks for social loneliness and emotional loneliness. While Maiden et al in the USA study 